WSRC-RP-94-516, Rev. O

Key Words: Ignition Sources

Waste Tanks

Deflagration

Probability

Frequency

Leaks

\title{
FREQUENCIES OF LEAKS AND PROBABILITY OF IGNITION SOURCES IN THE H-AREA TANK FARM (U)
}

Author:
D. S. Cramer

Issued Revision 0: May 15, 1994

Westinghouse Savannah River Company

Savannah River Site

Aiken, SC 29808

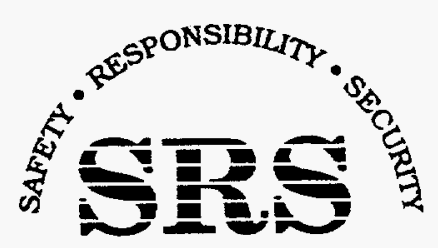

SAVANNAH RIVER SITE

PREPARED FOR THE U.S. DEPARTMENT OF ENERGY UNDER CONTRACT NO DE-ACO9-89SR18035

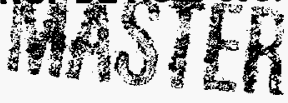




\section{DISCLAIMER}

This report was prepared as an account of work sponsored by an agency of the United States Government. Neither the United States Government nor any agency thereof, nor any of their employees, make any warranty, express or implied, or assumes any legal liability or responsibility for the accuracy, completeness, or usefulness of any information, apparatus, product, or process disclosed, or represents that its use would not infringe privately owned rights. Reference herein to any specific commercial product, process, or service by trade name, trademark, manufacturer, or otherwise does not necessarily constitute or imply its endorsement, recommendation, or favoring by the United States Government or any agency thereof. The views and opinions of authors expressed herein do not necessarily state or reflect those of the United States Government or any agency thereof. 


\section{DISCLAIMER}

Portions of this document may be illegible in electronic image products. Images are produced from the best available original document. 
Project: $\quad$ PRA

Document: $\quad$ WSRC-RP-94-516, Rev. 0

Title: $\quad$ Frequencies of Leaks and

Proability of Ignition Sources

in the H-Area Tank Farm (U)

Approvals:

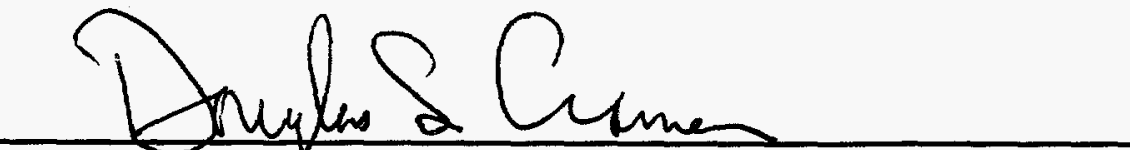

D. S. Cramer, Fe low Scientist, Safety Information Management \& Analysis Group, Author

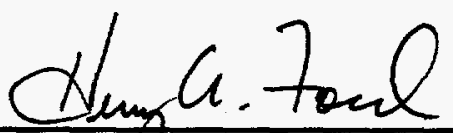

H. A. Fold, Senior Engineer, Risk Assessment Methodology Group, Reviewer

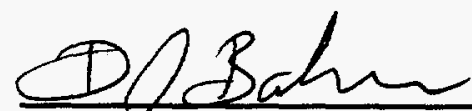

D. J Baker, Manager, Safety Information Management \& Analysis Group

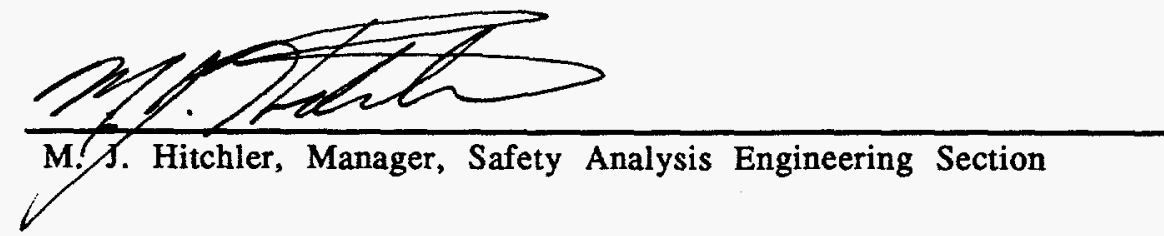

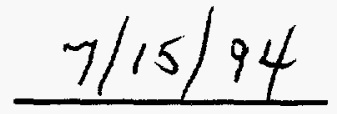

Date:

$7 / 15 / 94$

Date:

$2 / 15 / 94$

Date:

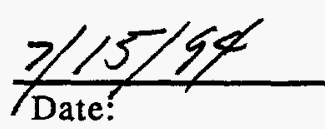




\section{ACKNOWLEDGMENT}

This report is an effort to estimate the probability of ignition sources in Waste Tank 48 and Filter Cell in the In-Tank Precepitation Facility as well as leak frequencies as a function of leak rate in connecting transfer lines. Contributions were made by J. R. Taylor as well as other supporting engineering personnel at SRS. Wherever possible, previous work in this field published at SRS, national laboratories and private industry was used to render this work cost effective. I would like to express my appreciation to everyone who took time out of their busy schedules for an interview or to provide needed information. Discussions with D. A. Pervis in the H-Area Tank Farm as well as personnel who have worked in both the F- and H-Canyons were an invaluable source of information. Appreciation is also expressed to $\mathrm{H}$. A. Ford for the time spent in careful review and the insightful comments provided by the Technical Review Group (TRG) who reviewed similar work at SRS which is utilized in arriving at the present results. 
SECTION

PAGE

EXECUTIVE SUMMARY 1

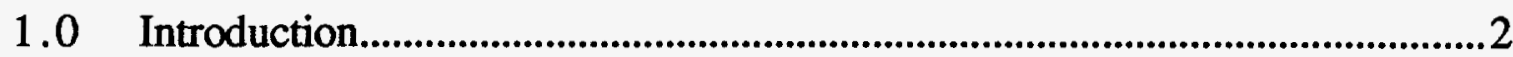

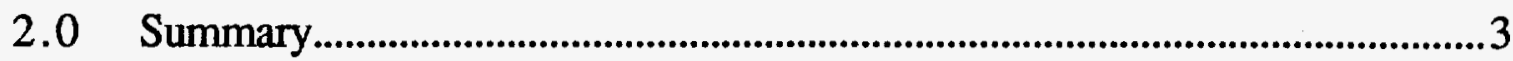

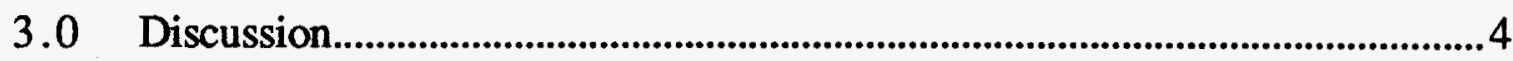

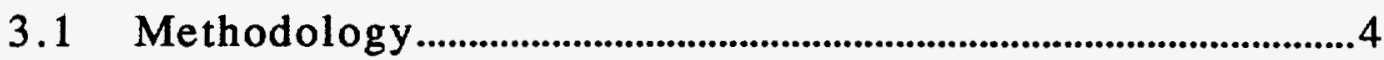

3.2 Assumption s...........................................................................................6

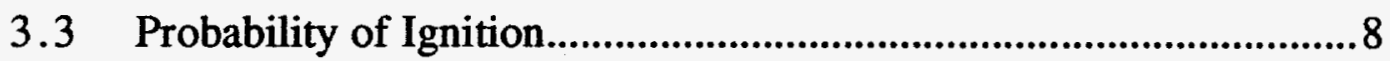

3.3.1 Small Leak Rates Existing Less than One Year............8

3.3.2 Small Leak Rates Existing More than One Year....... 10

3.3.3 Miscalibrations/Handling/Violation of Procedures 12

3.3.4 Combined Ignition Source Probabilities ....................... 14

4.0 Frequency of Leaks in the Tank 48 Annulus.................................... 15

4.1 Estimate \#1 Based on Generic Data........................................15

4.2 Estimate \#2 Based on SRS Data..............................................15

5.0 Frequency of Leaks in Hanford Connectors .......................................18

6.0 Frequency of Leaks in Double-Wall Transfer Lines.......................2 20

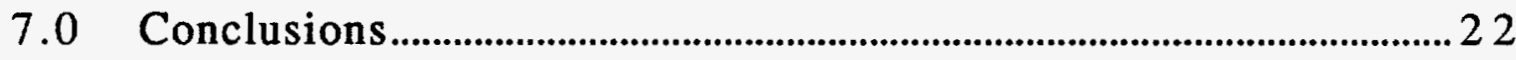

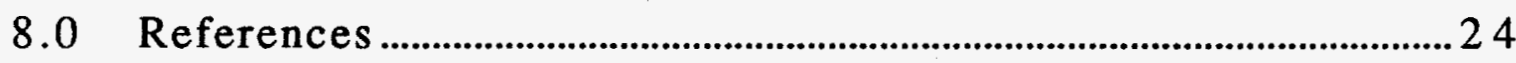


TABLE OF CONTENTS

FIGURES

PAGE

FIGURE 1. HISTOGRAM OF LEAKS IN THE REACTOR D2O

COOLING SYSTEMS.

26 
WSRC-RP-94-516, Rev. 0

\section{EXECUTIVE SUMMARY}

A value of $1.1 \mathrm{E}-3$ is estimated as the conditional probability that an ignition source will be present and start combustion, given first, that a leak of tetraphenylborate (TPB) has occurred in either the Tank 48 or 49 annulus or in the Filter Cell. The work reported here parallels a similar analysis which was performed and reviewed recently for deflagration of gases/vapors inside Tanks 48 or 49 . As before, a conservative margin is included by doubling the intermediate result to bound the industrial observation that in as many as $50 \%$ of the cases of deflagration, the source of ignition can not be determined. The probability of $1.1 \mathrm{E}-3$ is lower than the value reported previously for deflagration of gases/vapors inside Tank 48 or 49 due in part to the reduced movement of solids as compared to gas/vapor mixing and the reduced amount of electrical equipment. As developed here the value of $1.1 \mathrm{E}-3$ is a conditional probability which is a multiplier to apply to the frequencies calculated by the cut sets that describe scenarios in which TPB reaches the regions of concern due to breaches in the system boundary. That is, given that there is a leak of combustible material, $1.1 \mathrm{E}-3$ is the conditional probability that an ignition source will be present and start combustion.

Based on experience with over 4,000 Hanford connectors in F- and H-Canyons, the average failure rate is estimated to be $1.1 \mathrm{E}-6 / \mathrm{hr} /$ connector $(\sim 1.0 \mathrm{E}-2 / \mathrm{yr} /$ connector $)$ with a nominal leak rate of 100 gallons/yr, or 1.4 gallons in 5 days. Based on this information, the frequency is $4 \mathrm{E}-2 / \mathrm{yr}$ for a leak $\leq 100$ gallons in 5 days for the Hanford connectors plus transfer lines in the Filter Cell. Expressed alternatively, there is a $95 \%$ chance that there will be no leaks within the first year of operation with the Filter Cell. If a leak does occur, the average size leak will require more than a year to accumulate 100 gallons of slurry in the cell. The frequency for large leaks $\geq 100$ gallons in 5 days will be dominated by the single-wall transfer lines which have a total leak frequency of $1.2 \mathrm{E}-4 / \mathrm{yr}$, or there is a $95 \%$ chance that no leaks will occur within 427 years.

Studies imply that large leaks would flow to a sensor and be detected before drying and becoming susceptible to ignition. Small leaks are of the greatest concern since the reduced flow rate delays detection and allows time for the slurry to accumulate and dry before making contact with a potential source of ignition. A value of $2 \mathrm{E}-3 / \mathrm{yr}$ is recommended for the frequency of a small leak that can go undetected and deposit more than 900 gallons in the Tank 48 annulus. Given that there is a $2 \mathrm{E}-3$ probability that a small leak will occur in one year, there is a $95 \%$ chance that none of these leaks will occur in 25 years. Should a leak occur, the time it would take to accumulate 900 gallons would range from 18 days to 40 years where the longer times are most likely.

A value of $2.0 \mathrm{E}-6 / \mathrm{yr} / \mathrm{ft}$ is estimated as an upper bound for the frequency of all size leaks for doubled-wall transfer lines. Based on this value, leak frequencies are calculated to be less than $4 \mathrm{E}-4 / \mathrm{yr}$ for the transfer line from Tank 48 to the Filter Cell $(<200$ feet); $8 \mathrm{E}-4 / \mathrm{yr}$ for the transfer line from Tank 48 to Tank 49 ( $<400$ feet); and $4 \mathrm{E}-3 / \mathrm{yr}$ for the transfer line from Tank 49 to "Late Wash" Tank $(\sim 2,000$ feet $)$. In a double-wall transfer line, it is not possible to detect the onset of all common cause failures. Therefore, the remaining common cause failure modes which are difficult to detect are the dominate contributors to the failure rate. 


\subsection{INTRODUCTION}

Point estimates are developed for the probability of an ignition source for tetraphenylborate (TPB) solids in H-Area which leak into the annulus of Tank 48 and/or in the Filter Cell. Additionally, leak frequencies and leak rates are estimated for: the inner wall of Tank 48; Hanford connectors and single-wall transfer lines in the Filter Cell of the In-Tank Precipitation (ITP) Facility; and the double-wall transfer lines between Tank 48, the Filter Cell, Tank 49 and the "Late Wash" Tank.

The work reported here parallels a similar analysis [1] which was performed and reviewed recently for deflagration of gases/vapors inside Tanks 48 or 49 . As before, a conservative margin is introduced by doubling the probability of ignition. This acknowledges the industrial observation [2] that in as many as 50\% of the cases of "industrial fires and explosions", the source of ignition can not be determined. It is assumed that doubling the results will bound the contribution from static electricity which is not expected to be a dominant contributor [25].

SRS has accumulated a significant amount of experience with thousands of Hanford connectors in $\mathrm{F}$ - and $\mathrm{H}$-Canyons. An average frequency as well as an average leak rate for Hanford connectors can, therefore, be developed.

Other studies [3] with TPB solids are considered in this work as well as bounds on large leaks which would flow [24] to a sensor and be detected before drying and becoming susceptible to ignition. With small leaks, flow towards a source of ignition is reduced and drying may take place before contact with a potential source of ignition.

A frequency is estimated for leaks of any size in single-wall transfer lines in the Filter Cell and in doubled-wall transfer lines from Tank 48 to the Filter Cell, Tank 48 to Tank 49, and Tank 49 to the "Late Wash" tank.

As developed here the value of $1.1 \mathrm{E}-3$ is a conditional probability which is a multiplier to apply to the frequencies calculated by the cut sets that describe scenarios in which TPB reaches the regions of concern due to breaches in the system boundary. That is, given that there is a leak of combustible material, 1.1E-3 is the conditional probability that an ignition source will be present and start combustion.

Some values are expressed for comparison to 100 gallons in 5 days for the Filter Cell and a total of 900 gallons/yr for the Tank 48 or 49 annulus because these limits are of significance in a larger effort in the safety analysis for Tanks 48,49 and the Filter Cell.

Although this work addresses internal fire, it does not address external fires such as motor or diesel fires or other external events such as seismic events, tornado, etc. 
WSRC-RP-94-516, Rev. 0

\subsection{SUMMARY}

A value of $1.1 \mathrm{E}-3$ is estimated for the probability of an ignition source for tetraphenylborate solids present in the Tank 48 or 49 annulus or in the Filter Cell of the ITP Facility. This work parallels a similar analysis [1] which was performed and reviewed recently for deflagration of gases/vapors inside Tanks 48 or 49 . As before, a conservative margin is included by doubling the intermediate result to obtain 1.1E-3. This is done to bound the industrial observation [2] that in as many as 50\% of the cases of "industrial fires and explosions", the source of ignition can not be determined. It is assumed that doubling the results will bound the contribution from static electricity which is not expected to be a dominant contributor [25]. The probability of $1.1 \mathrm{E}-3$ is lower than the value reported previously for deflagration of gases/vapors inside Tank 48 or 49 due to the reduced movement of solids as compared to gas/vapor mixing and the reduced amount of electrical equipment such as analyzers and level sensors.

Based on SRS experience with over 4,000 Hanford connectors in F- and H-Canyons, the average failure rate is recommended as $1.1 \mathrm{E}-6 / \mathrm{hr} /$ connector $(-1.0 \mathrm{E}$ $2 / \mathrm{yr} /$ connector with a nominal leak rate of 100 gallons/yr, or 1.4 gallons in 5 days). Based on this information, the frequency for a leak $\leq 100$ gallons in 5 days is $4 \mathrm{E}-2 / \mathrm{yr}$ for four Hanford connectors plus 100 feet of transfer lines in the Filter Cell which are under the highest pressure and contain the largest concentrations of tetraphenylborate solids. Expressed alternatively, there is a 95\% chance that there will be no leaks within the first year of operation with the Filter Cell. If a leak does occur, the average size leak will require more than a year to accumulate 100 gallons of slurry in the cell. The frequency for large leaks $\geq 100$ gallons $/ 5$ days will be dominated by the 100 feet of single-wall transfer lines in the Filter Cell which have a leak frequency of $1.2 \mathrm{E}-4 / \mathrm{yr}$. Expressed alternatively, for large leaks $\geq 100$ gallons $/ 5$ days, there is a $95 \%$ chance that no leaks will occur within 427 years of operation with the Filter Cell.

Studies [3] have shown that large leaks (approaching 50 gallons/day) would flow [24] to a sensor(s) and be detected before drying and becoming susceptible to ignition. Small leaks are of the greatest concern since the reduced flow rate delays detection and allows time for the slurry to accumulate and dry before making contact with a potential source of ignition. With small leaks, flow towards a source of ignition is reduced and, in some cases, may even be arrested, although, no credit is given in this analysis for this effect. A value of $2 \mathrm{E}-3 / \mathrm{yr}$ is recommended for the frequency of a small leak that can go undetected and deposit more than 900 gallons in the Tank 48 annulus. Given that there is a $2 \mathrm{E}-3$ probability that a small leak will occur in one year, there is a $95 \%$ chance that none of these leaks will occur in 25 years. Should a leak occur, the time it would take to accumulate 900 gallons would range from 18 days to 40 years where the longer times are most likely. 
A value of $2.0 \mathrm{E}-6 / \mathrm{yr} / \mathrm{ft}$ is estimated as an upper bound for the frequency of all size leaks for doubled-wall transfer lines. Based on this value, leak frequencies are calculated to be less than $4 \mathrm{E}-4 / \mathrm{yr}$ for the transfer line from Tank 48 to the Filter Cell ( $<200$ feet); less than $8 \mathrm{E}-4 / \mathrm{yr}$ for the transfer line from Tank 48 to Tank 49 ( $<400$ feet); and less than $4 \mathrm{E}-3 / \mathrm{yr}$ for the transfer line from Tank 49 to "Late Wash" Tank $(-2,000$ feet). In a double-wall transfer line, it is not possible to detect the onset of all common cause failures (e.g., sampling the annular volume). Therefore, the remaining common cause failure modes which are more difficult to detect are the dominant contributors to the failure rate of $2.0 \mathrm{E}-6 / \mathrm{yr} / \mathrm{ft}$.

\subsection{DISCUSSION}

In developing the "conditional probability of an ignition source", the terms "probability of an ignition source", "probability of ignition", "ignition probability", "probability of deflagration" and "probability of combustion" are often interchanged. It is assumed that if a high energy ignition source occurs and comes in contact with dry tetraphenyllborate solids for an extended period of time, then ignition will occur and combustion will follow. In the following, the term tetraphenylborate solids is usually replaced with TPB.

The probability of an ignition source is calculated as a conditional probability. That is, the calculation for the probability of an ignition source assumes that the TPB solids in the slurry are dry and sufficient to sustain continuous combustion once ignited. Therefore, the conditional probability is used as a multiplier which is combined with all accident scenarios (cut sets) where the leaks exceed 900 gallons total accumulated slurry in the Tank 48 annulus and 100 gallons ( $39 \mathrm{Ci} /$ gallon) in the Filter Cell.

Combustion can be avoided if either there are: (1) no leaks, (2) no sources of ignition, or (3) insufficient TPB solids have accumulated from the leak.

\subsection{METHODOLOGY}

The following outlines the methodology used in this analysis:

- Develop one value for the conditional probability to be used as a multiplier with all accident scenarios (cut sets) where the leaks exceed specified limits for the Tank 48 and Filter Cell.

- Develop a conditional probability for the occurrence of sources of ignition with conservatisms to insure that the final result is a bounding estimate. 
- Where available use onsite and offsite information, F- and H-Canyons, SRS reactors, publications and industry.

- Double the fault tree result to bound industrial experience [2] which shows that in as many as half of the cases of industrial fires and explosions investigated, the ignition source is not determined.

- Since there are seasonal changes in the chance that lightning will strike close to ITP, for this probabilistic analysis, use an average for the frequency of lightning strikes that cause electrical sparks and damage in electronics. The frequency averaged over all seasons and abnormal weather conditions is obtained by using site-specific data on lightning induced sparks in safety equipment gathered over 60 reactor-years of SRS reactor experience.

- If there is a small leak, it will take a long time to accumulate slurry in excess of operating limits. During this time, a lightning strike may occur close to Tank 48,49 or the Filter Cell. A single electrical discharge will not ignite the TPB [3] due to its short duration in contrast to a gas/vapor [1, 3]. To cause ignition, lightning must damage electrical equipment which in turn must provide a continuous discharge of energy which is sufficient to cause combustion. Damage to electrical equipment will be discovered and repaired no later than the next cycle of calibration, tests or preventive maintenance.

- Equipment failures may occur and go undetected before the next calibration, test, or preventive maintenance (assumed quarterly). Since this may occur at any time in this interval, failure probabilities are calculated using half of the interval. The equipment of concern is sensors, cables and electronics which operates the level sensors inside the annulus.

This study combines key sources of information to evaluate the ignition probability:

- Site-specific data specific to SRS reactors.

- Site-specific data specific to Tanks 48 and 49 and prior operation of $\mathrm{F}$ - and H-Canyons (e.g.,leak frequency and rate for Hanford Connectors).

- Generic information (failure rates, manufacturer specs, etc.) including similar analyses performed offsite.

Uncertainty analyses propagate uncertainties in the input parameters through the model into the results. Because there are a number of conservatisms identified throughout this development, an uncertainty analysis is not performed at this time. 


\subsection{ASSUMPTIONS}

The following assumptions are used in the calculation for the conditional probability:

- If a high energy ignition source occurs and comes in contact with dry TPB, then ignition will occur and combustion will follow.

- All electronics are assumed to be powered at all times.

- There are seasonal changes in the chance that lightning will strike close to the Tank Farm. For this probabilistic analysis, it is assumed that an average frequency can be used for the frequency of lightning strikes causing damage to electrical equipment. It is damaged equipment that provides a continuous deposition of energy which in turn may lead to combustion not the electrical discharge from a single lightning strike. (For gases/vapors, a single strike is assumed to cause ignition [1]). It is further assumed that this frequency can be taken from lightning induced sparks in safety equipment in 60 reactor-years of SRS experience with reactors. Electrical sparking may not cause ignition [2].

- Doubling the probability of an ignition source bounds the industrial observation that in as many as $50 \%$ of the cases of combustion the source of ignition can not be determined.

- Static electricity, as a contributor to the ignition probability, is normally precluded by procedures. Therefore, a violation of a procedure must occur before static electricity can have any impact. Where static electricity may not be precluded by procedures, it is assumed that its contribution is included within the additional margin introduced by doubling the result to account for industry's observation that in as many as $50 \%$ of the reported cases of combustion the source is not determined. Others [25] have evaluated static electricity in similar analyses and have concluded that it is not the dominant contributor to ignition.

- Operating limits will be 900 gallons total accumulated slurry in the Tank 48 annulus and 100 gallons ( $39 \mathrm{Ci} /$ gallon) in the Filter Cell based on the safety analysis of the operation of Tanks 48, 49 and the Filter Cell in the ITP Facility.

- Calculations are based on calibration, tests and preventive maintenance being performed on a quarterly basis. 
- Procedures and instructions are followed with close supervision (e.g., quarterly checks, hydrostatic testing of Hanford connectors and transfer lines and jumpers used in the ITP Filter Cell, etc.).

- Any damage to sensors, electronics, cables, etc. will be discovered and repaired no later than the next scheduled test, calibration or preventive maintenance is performed. The probability for failure to do so has only a second order effect on the results.

- Distribution of probability values for possible failure modes can be characterized by a lognormal distribution.

- There is always enough TPB to ignite and sustain burning once started.

- Large leaks in Tanks 48 or 49 will never exceed the maximum leak rate of 50 gallons/day observed once in an atypical C-Reactor.

- A leak of 50 gallons/day will spread out [24] before drying and, therefore, be detected by one or more sensors followed by a shutdown of operations.

- Slurry from small leaks is delayed in coming in contact with a sensor(s) and, therefore, could go undetected for a long period of time (months).

- Slurry from all small leaks will dry by the time it builds up enough material to come into contact with a source of ignition because both the solids and ignition source can originally be in widely separated positions. Therefore, no credit is taken for the fact that the TPB may be too wet to ignite.

- Slurry from all large leaks does not dry [24] before it builds up enough material to come into contact with a source of ignition because of the fast rate of movement from the leak to the sensor. Therefore, full credit is taken for the fact that the TPB will be too wet to ignite.

- The shape of leak frequency versus leak rate for similar large systems due to similar failure mechanism (cracks in stainless steel) will follow the approximate shape given for leaks in the $\mathrm{D}_{2} \mathrm{O}$ cooling water system. SRS data on stainless steel reactor systems over 30 years [16] is consistent with Hanford data on carbon steel single-wall tanks [23] over a comparable length of time.

- All of the leaks $\leq 1 \mathrm{~kg}$ on the histogram of leaks versus leak rates are small enough to escape immediate detection and will accumulate dried material which may be subsequently ignited. 
- The volume of a drop of slurry from a leaking Hanford connector is a sphere with a 0.25 inch diameter.

- The probability for equipment damage by operating personnel which is included in these estimates is $1.3 \mathrm{E}-1$ which is obtained from the sum of two conservative probability values: $2.4 \mathrm{E}-2$ for a procedure violation [5] plus 1.05E-1 for miscalibration [6].

\subsection{PROBABILITY OF IGNITION}

\section{Ignition Probability for Solid TPB in the Tank 48 or 49 Annulus and Filter Cell}

The ignition probability is a conditional probability that an ignition source is present and effective in igniting dry solid ( $\sim 95 \mathrm{wt} \%$ potassium) tetraphenylborate (TPB) which may be present. In the following, all dry solids will be referred to simply as TPB. The conditional probability is obtained by multiplying the probabilities that specific conditions will occur and summing over the possible scenarios in which these conditions might develop. The ignition probabilities for the Filter Cell and Tank 48 or 49 Annulus (Double Wall) are developed as one value since estimates are conservative and general enough to bound both applications.

\subsubsection{Small Leak Rates Existing for Less than One Year.}

The following seven factors are combined:

1. (consider the frequencies of events [e.g., lightning, power surge, etc.] that may cause electrical damage and multiply by a nominal number of sensors/equipment in the cell including important connecting controllers/electronics inside and outside the cell that could be damaged.)

2. (failure mode involves sparking and/or heating)

3. (sparking deposits enough energy to cause ignition)

4. (sparking is not stopped by operator intervention.)

5. (solids are in contact with sparking/heating. Note: contact is different from gas mixtures.)

6. (TPB is dry enough to ignite)

7. (there is enough TPB to ignite and sustain burning) 
The combination of these seven factors yields a probability of:

Probability 1.9E-4 $=(2.5 \mathrm{E}-1)(0.05)(0.50)(0.30)(0.10)(1.0)(1.0)$

An explanation of the quantification of each of the seven factors is given as follows:

1. (2.5E-1 from 2.3E-5/hr, Table E.15, Ref. 7, from SRS reactor experience with lightning strikes that directly affected safety equipment in 9 events in 45 reactor years times $24 \mathrm{hrs} /$ day, times 30 days/month, times 3-month quarterly inspection interval, times $1 / 2$ the inspection interval, times 10 which bounds the number of sensors and electrical connections (includes motors that drive hydraulically operated valves, etc.). One-half the inspection interval is used since the leak (or ignition source) can begin at any random point in that interval. It is assumed that damage exists only until the next quarterly check when it would be discovered and repaired. The probability that the damage is not discovered or repaired is not included since it is a second order contributor to the probability and is easily absorbed in the uncertainties. The probabilities for miscalibration and failure to follow maintenance procedures are considered below in Sec. 3.3.3.

2. times $(0.05$ Only a small subset of all the possible failure modes are of concern here. The value of 0.05 is the probability that specific failure modes occur and produce electrical sparking or heating in the cable, probe or components in the volume of concern. Following the arguments used in Ref. [1], the value of 0.05 is obtained by taking a very conservative $95 \%$ upper bound of 0.500 and a credible $5 \%$ lower bound of 0.005 . By assuming that the distribution of probability values can be characterized by a lognormal distribution, the value of 0.05 is taken as a median value with an error factor of 10 . That is, there is a $50 \%$ chance that the probability is either less than 0.05 , or greater than 0.05 .)

3. times $(0.50$ this is the conditional probability that if sparking occurs, the sparking provides enough sustained energy to cause ignition. A value of $50 \% / 50 \%$ is used since sparking may occur over a long enough time to promote ignition.)

4. times $(0.30$ the probability that sparking is not noticed, or noticed but not corrected, during the course of normal rounds. This value includes the possibility that the failure is discovered, but it is not repaired correctly or removed from service. This value was used previously for similar applications [1]). It is applied here as a probability that the sparking will not 
be stopped before the next quarterly check mentioned as part of the initiator in step \#1 above. It is assumed in step \#1 that at the next quarterly inspection sparking will be stopped (probability equal to 1.0 ).

5. times $(0.10$ an average probability that the solids are located close enough to the sparking probe, cable or component for effective energy transfer. This additional reduction does not appear with deflagration of gases/vapors. It represents the fact that the solids that have leaked from the system do not move easily toward the ignition source as gases/vapors do. A detailed determination of this probability would require that many configurations be evaluated and averaged. In lieu of this alternative, a value of 0.10 is proposed based on engineering judgment.)

6. times (1.00 assumes that the TPB is always dry enough to ignite. That is, no credit is taken for the fact that the TPB may be too wet to ignite.)

7. times (1.00 assumes that there is enough TPB to ignite and sustain burning.)

\subsubsection{Small Leak Rates Existing for More than One Year:}

The following seven factors are combined:

1. (wire damaged during installation, or wire insulation degraded with time over several years, multiplied by a nominal number of sensors, electrical connections and components in the volume of concern.)

2. (failure mode involves sparking and/or heating)

3. (sparking deposits enough energy to cause ignition)

4. (sparking is not stopped by operator intervention. Neither cable damage or sparking are discovered after several cycles of calibration, test, or maintenance, thus, 
the failure is due to some persistent problem or error (e.g., common causes) which occurs in calibration or maintenance during scheduled checks and exits for a year or more.)

5. (solids are in contact with sparking/heating. Note: contact is different from gas mixtures.)

6. (TPB is dry enough to ignite)

7. (there is enough TPB to ignite and sustain burning)

The combination of these seven factors yields a probability of:

Probability 7.5E-5 $=(1.00)(0.05)(0.50)(0.03)(0.10)(1.0)(1.0)$

An explanation of the quantification of each of the seven factors is given as follows:

1. (1.00 This value is set to unity (i.e., certainty) that at least one component or wire out of several is damaged on installation or degrades after years of service. By setting this value to 1.0 it is not necessary to specify the number of sensors/equipment and remote electrical connections including motors that drive hydraulically operated valves. Wiring in approved conduit is not expected to be a contributor.)

2. times $(0.05$ Only a small subset of all the possible failure modes are of concern here. The value of 0.05 is the probability that specific failure modes occur and produce electrical sparking or heating in the cable, probe or components in the volume of concern. Following the arguments used previously [1], the value of 0.05 is obtained by taking a very conservative $95 \%$ upper bound of 0.500 and a credible $5 \%$ lower bound of 0.005 . By assuming that the distribution of probability values can be characterized by a lognormal distribution, the value of 0.05 is taken as a median value with an error factor of 10 . That is, there is a $50 \%$ chance that the probability is either less than 0.05 , or greater than 0.05 .)

3. times $(0.50$ this is the conditional probability that if sparking occurs, the sparking provides enough energy to cause ignition. A value of $50 \% / 50 \%$ is used since sparking may occur over a long enough time which would promote ignition.) 
4. times $(0.03$ for the probability that damaged equipment is not discovered, or is discovered but not repaired correctly, or is not removed from service. The value of 0.03 is obtained [8-9] by using 0.3 for the probability that operators will fail to fix this equipment during the first quarterly check multiplied by 0.1 for the common human errors that will cause the operators to continue to fail to fix this problem on subsequent quarterly checks so that a period of time greater than one year may accumulate during which time electrical degradation exists.)

5. times $(\underline{0.10}$ an average probability that the solids are located close enough to the sparking probe, cable or component for effective energy transfer. This additional reduction does not appear with deflagration of gases/vapors. It represents the fact that the solids that have leaked from the system do not move easily toward the ignition source as gases/vapors do. A detailed determination of this probability would require that many configurations be evaluated and averaged. In lieu of this alternative, a value of 0.10 is proposed based on engineering judgment.)

6. times (1.00 assumes that the TPB is always dry enough to ignite. That is, no credit is taken for the fact that the TPB may be too wet to ignite.)

7. times (1.00 assumes that there is enough TPB to ignite and sustain burning.)

\subsubsection{Miscalibrations/Mis-handling of Equipment/Violations of Procedures}

The following factors are considered:

1a. (chance for procedure violation or miscalibration.)

1b. (significant number of procedures or calibrations performed since the last quarterly check or maintenance.) 
1c. (error is not discovered by coworkers or supervision, or that it is discovered but it is not corrected or undone effectively.)

2. (subset of all procedure violations which produces electrical sparking or heating in the cable, sensor or component in the volume of concern.)

3. (probability that sparking provides enough energy to cause ignition.)

4. (operator or supervisor fails to stop the sparking.)

5. (average probability that the solids are located close enough to the sparking sensor, cable or component for effective energy transfer.)

6. (probability that TPB is dry enough to ignite.)

7. (probability that there is enough TPB to ignite and sustain burning.)

The combination of these factors yields a probability of:

Probability $2.9 \mathrm{E}-4=(1.3 \mathrm{E}-1)(9)(0.10)(0.05)(0.50)(1.0)(0.10)(1.0)(1.0)$

An explanation of the quantification of each of these factors is given as follows:

1a. (1.3E-1 is the sum of 2.4E-2 for a procedure violation [5] plus a conservative probability of $1.05 \mathrm{E}-1$ for a miscalibration [6]. This value is assumed to be conservative and to include equipment mistreatment.

1b. times ( 9 or fewer major procedures or calibrations performed since the last quarterly check or maintenance.)

1c. times $(0.1$ is the probability [8-9] that the error is not discovered by coworkers or supervision, or that it is discovered but it is not corrected or undone effectively.)

2. times $(\underline{0.05}$ Only a small subset of all procedure violations are of concern here. The value of 0.05 is the probability that specific human error(s) occurs and produces electrical sparking or heating in the cable, probe or equipment in the volume of concern.) Similar to the arguments developed in earlier work [1], the value of 0.05 is obtained by taking a conservative $95 \%$ upper bound of 0.500 
and a credible $5 \%$ lower bound of 0.005 . By assuming that the distribution of probability values can be characterized by a lognormal distribution, the value of 0.05 is taken as a median value with an error factor of 10 . Therefore, there is a $50 \%$ chance that the probability is either less than 0.05 , or greater than 0.05 .)

3. times $(0.50$ this is the conditional probability that if sparking occurs, the sparking provides enough energy to cause ignition. A value of $50 \% / 50 \%$ is used since sparking may occur over a long enough time to insure ignition.)

4. times $(1.00$ no credit is given for the operator or supervisor stopping the sparking since to reach this step since their error(s) may have already contributed to the condition.)

5. times $(\underline{0.10}$ an average probability that the solids are located close enough to the sparking probe, cable or component for effective energy transfer. This additional reduction does not appear with deflagration of gases/vapors. It represents the fact that the solids that have leaked from the system do not move easily toward the ignition source as gases/vapors do. A detailed determination of this probability would require that many configurations be evaluated and averaged. In lieu of this alternative, a value of 0.10 is proposed based on engineering judgment.)

6. times (1.00 no credit is taken here for the probability that TPB may be too wet to ignite.)

7. times (1.00 no credit is taken here for the probability that there is not enough TPB to ignite and sustain burning.)

\subsubsection{Combined Ignition Source Probabilities}

The sum of the three scenarios is $5.6 \mathrm{E}-4$ obtained from adding the three terms $(1.9 \mathrm{E}-4)+(7.5 \mathrm{E}-5)+(2.9 \mathrm{E}-4)$ developed in Sections 3.3.1, 3.3.2 and 3.3.3 above, respectively. 
This analysis parallels a similar analysis which was performed and reviewed recently $[1,10]$ for deflagration of gases/vapors above the lower flammability limit inside Tank 48 and 49 . Following that methodology, another conservative margin is included here in the ignition probability by doubling the value of $5.6 \mathrm{E}-4$ to obtain 1.1E-3. This is done to bound the industrial observation [2] that in as many as $50 \%$ of the cases of "industrial fires and explosions", the source of ignition can not be determined. As before [1], it is assumed that doubling the value also bounds the contribution from static electricity consistent with the fact that others [4] have evaluated static electricity and have concluded that it is not the dominant contributor.

Thus, the final value of $1.1 \mathrm{E}-3$ is recommended for the ignition probability in the Tank 48 or 49 annulus or in the Filter Cell of the ITP Facility. The ignition probabilities for the tank annulus and the filter cell are developed as one value since there is a similarity and/or overlap in the root causes, equipment, uncertainties and locations of susceptibility.

\subsection{FREQUENCY OF LEAKS IN THE TANK 48 ANNULUS}

\subsection{Estimate \#1 Based on Generic Data}

The frequency of leaks in large tanks is $8.8 \mathrm{E}-4 / \mathrm{yr}$ obtained from a generic value of $1 \mathrm{E}-7 / \mathrm{hr}$ [11] times $8760 \mathrm{hrs} / \mathrm{yr}$.

\subsection{Estimate \#2 Based on SRS Data}

For leaks in large ( $15^{\prime}$ diameter) tanks, leak frequencies are calculated based on experience with SRS reactors combined with experience obtained in the H-Area Tank Farm:

In 30 years of operation, 18 cracks were detected in the C-Reactor tank wall. The leak rate through these cracks was small enough that reactor operations could continue. During that time, additional growth of these cracks was closely monitored. The maximum crack length was $12^{\prime \prime}$. Only two significant leaks were observed: $\sim 50$ gallons/day [12] and $\sim 17$ gallons/day. The root causes for the cracks/leaks in C-Reactor are now understood and were controlled and thus eliminated [13] during the design and construction of Tanks 48 and 49 . Therefore, the leak rate of 50 gallons/day obtained with CReactor is used as a conservative bound for worst-case leaks in Tanks 48 or 49 .

Experience with the remaining SRS reactors indicates that there have been no cracks or leaks in the reactor tank walls in each of $P, K, L$ and $R$-Areas $[12,14]$. Because the reactors operated less than $100 \%$ of the time, the effective number of reactor-years associated with no cracks/leaks is approximately 86 . 
On-going inspections have shown that there have been no leaks in 381 tankyears [13] in double-wall tanks in H-Area. This data is consistent with experience at the Hanford Tank Farm [23]. This implies that root causes that may lead to cracks/leaks are well understood and under adequate control.

A tank failure frequency of $1.1 \mathrm{E}-3 /$ tank-year is obtained from dividing 0.5 (zero occurrences) by ( 86 SRS reactor $+381 \mathrm{H}$-Area) tank-years. The value of 0.5 is used as a statistical estimator for calculating the mean value when there have been zero occurrences $[11,15]$. The result of $1.1 \mathrm{E}-3 /$ tank-year is consistent with the value of $8.8 \mathrm{E}-4 /$ tank-year obtained above as Estimate \#1 based only on generic data.

Next, the difference between small and large leaks is characterized and a conservative bound on the amount of material associated with small leaks is established for H-Area Tanks:

First, assume that if a large leak occurred in Tanks 48 or 49 that it would never exceed the maximum leak rate of 50 gallons/day observed once in CReactor. This data point agrees with 30 years of experience at the Hanford Tank Farm with single-wall tanks [23]. Using the data from C-Reactor, no credit is taken for the fact that: (1) the viscosity of the liquid in Tank 48 or 49 as compared to $\mathrm{D}_{2} \mathrm{O}$ cooling water in C-Reactor should produce a smaller leak rate given the same crack formation and opening area; or (2) crack/leak formation is now understood and adequately managed. A leak of 50 gallons/day would require 18 days to accumulate 900 gallons in the Tank 48 or 49 annulus. Studies [3] on a smaller scale suggest that this amount of slurry will spread out before drying. It is assumed, therefore, that this leak rate will be detected by one or more sensors and operations shutdown.

Second, the amount of material associated with small leaks is quantified. It is assumed that slurry from small leaks is delayed in coming in contact with a sensor(s) and, therefore, could go undetected for a long period of time (months). Furthermore, because both the solids and ignition source can originate in widely separated positions, it is assumed that the slurry will be dry by the time deposits come into contact with a source of ignition.

Third, Figure 1 presents a histogram based on reported leaks in reactor $\mathrm{D}_{2} \mathrm{O}$ (moderator) cooling water systems over 36 reactor years [16]. The concepts of fractal statistics [17] suggest that the shape of leak frequency versus leak rate for similar large systems due to similar failure mechanism (cracks in stainless steel) will follow this approximate shape. It is assumed that this is the case here. The histogram indicates that were 67 small leaks each totaling $\leq 1 \mathrm{~kg}$. It is assumed that all of these leaks are small enough to escape immediate detection and will accumulate dried material which could be subsequently 
ignited. It is somewhat arbitrary as to where the threshold should be set for those leaks which are, with certainty, large leaks. A sensitivity study was performed using exponential fits to the data as well as log-log fits. The study showed that a credible approach which is also the most conservative is to identify the 67 leaks in the first bin $(\leq 1 \mathrm{~kg})$ as small and the remaining 37 leaks as large. This implies that there are approximately 1.8 times more small leaks than large leaks. As discussed above, large leaks are bounded by a maximum leak rate of 50 gallons/day with a frequency of $1.1 \mathrm{E}-3 /$ tank-year. Because of their leak rate, it is credible that they will be detected quickly [24]. On the other hand, the small leaks will have a frequency of $2.0 \mathrm{E}-3 /$ tank-year (obtained from 1.1E-3/tank-year times 1.8). The probability of incurring a small leak in one year is $2 \mathrm{E}-3$, or expressed alternatively, there is a $95 \%$ chance that it will take 25 years before one of these small leaks occurs:

$$
\text { Probability (no leaks in } x \text { years, } x=25)=\exp \{(-2 E-3)(25 \text { years })\}=0.95
$$

Should a small leak occur, it would require significantly more than 18 days for it to accumulate 900 gallons. Small leaks are, therefore, the dominant contributor to the combustion of solids.

A second calculation indicates that the specific histogram partitioning chosen above yields conservative results. In this calculation, the histogram is used again to obtain the relative shape of the curve, but a portion further out on the histogram is associated with large leaks. For example, if the threshold for large leaks is set $>800 \mathrm{~kg}$, there are 8 leaks $>800 \mathrm{~kg}$ such that the ratio of small $(\leq 1 \mathrm{~kg})$ to large leaks is 8.4 (67 divided by 8 ). Large leaks continue to be associated with a frequency of $1.1 \mathrm{E}-3 /$ tank-year and bounded by a 50 gallon/day leak rate. However, the frequency of small leaks increases to 9.2E$3 /$ tank-year (1.1E-3 times 8.4) while the upper bound on the small leak rate decreases to $6.3 \mathrm{E}-2$ gallons/day ( 50 gallons/day times $1 \mathrm{~kg}$ divided by $800 \mathrm{~kg}$ ). The probability of incurring a small leak in one year becomes $9.2 \mathrm{E}-3$, or expressed alternatively, there is a $95 \%$ chance that it will take 5.6 years before one of these small leaks occurs:

$$
\text { Probability (no leaks in } x \text { years, } x=5.6)=\exp \{(-9.2 E-3)(5.6 \text { years })\}=0.95
$$

Should a small leak occur, it would require more than 40 years to accumulate 900 gallons in the Tank 48 annulus. Therefore, the effect of using a higher threshold on the histogram for large leaks is that the frequency of small leaks increases but their leak rate compensates. The net effect is that all other choices of partitioning the large leaks using this histogram yields results that are bounded by the first choice for partitioning developed above. This conclusion is consistent with data obtained with single-wall tanks at the Hanford Tank Farm [23]. 


\subsection{FREQUENCY OF LEAKS IN HANFORD CONNECTORS:}

Based on SRS experience with several thousand Hanford connectors, the average failure rate and nominal leak rate are estimated. The leak frequency is then calculated for a configuration of four Hanford connectors plus approximately 100 feet of single-wall transfer lines in the Filter Cell which are under pressure and contain tetraphenylborate solids. The frequencies for leaks greater than and less than 100 gallons in 5 days are also calculated.

Interviews were held with three operators which had different experience with the operation of F- and H-Canyon during conditions of full and, more recently, reduced production. The following table summarizes those interviews:

\section{Interview Data on Leaking Hanford Connectors}

\begin{tabular}{|c|c|c|c|c|c|}
\hline $\begin{array}{l}\text { Employee/ } \\
\text { Experience }\end{array}$ & $\begin{array}{l}\text { Canyons } \\
\text { Production } \\
\text { Status }\end{array}$ & $\begin{array}{l}\text { Estimate of } \\
\text { Number of } \\
\text { Connectors } \\
\text { in Service } \\
\end{array}$ & $\begin{array}{l}\text { Estimate* of } \\
\text { Number of } \\
\text { Connectors } \\
\text { Leaking/year }\end{array}$ & $\begin{array}{l}\text { Calculated } \\
\text { Failure Rate } \\
\text { /hr/connector }\end{array}$ & $\begin{array}{l}\text { Number of } \\
\text { Drips/min }\end{array}$ \\
\hline $\begin{array}{l}1 \\
\text { several } \\
\text { years }\end{array}$ & Reduced & $\begin{array}{l}\text { "thousands" } \\
\text { use } 2000\end{array}$ & $\begin{array}{l}\text { estimated } \\
\qquad 20\end{array}$ & $1.1 \mathrm{E}-6 / \mathrm{hr}$ & " 1" \\
\hline$\stackrel{2}{\text { experienced }}$ & Reduced & $1400-1500$ & $\begin{array}{l}\text { "teen's" } \\
\text { use } 15\end{array}$ & $1.1 \mathrm{E}-6 / \mathrm{hr}$ & $" 1$ to $10 "$ \\
\hline $\begin{array}{l}3 \\
\text { experienced }\end{array}$ & Full & $\sim 4500$ & $\begin{array}{l}\text { every } 1 \text { to } 3 \\
\text { use } 2\end{array}$ & $4.6 \mathrm{E}-6 / \mathrm{hr}$ & "couple" \\
\hline
\end{tabular}

* Hanford Connectors that leak can usually be stopped by torquing (impacting).

These results are in general agreement with a source of generic data recently compiled and published at SRS [11] which recommends a value of $1.0 \mathrm{E}-6 / \mathrm{hr}$. There is a difference in the procedure by which Hanford connectors are placed into service in the F- and H-Canyons as compared to the Filter Cell. Normally, plumbing placed into service in the canyons is flushed with water. However, it does not undergo hydrostatic testing as the plumbing will be in the Filter Cell. This difference in checkout should improve the detection of leaking connectors and allow for correction before production runs are made. Therefore, the lower failure rate of $1.1 \mathrm{E}-6 / \mathrm{hr}$ is recommended for Hanford connectors in the Filter Cell instead of an aggregate of the above values which would have included the high value of $4.6 \mathrm{E}$ $6 / \mathrm{hr}$. There still remains some conservatism in the value of $1.1 \mathrm{E}-6 / \mathrm{hr} /$ connector 
when calculating the probability of a leak as $9.6 \mathrm{E}-3 /$ connector-year (from $1.1 \mathrm{E}-6 / \mathrm{hr}$ times $8760 \mathrm{hrs} / \mathrm{yr}$ ) but it is not assessed at this time.

To determine leak rates from Hanford connectors, first the volume of a drop of slurry is calculated to be $3.7 \mathrm{E}-5$ gallons assuming that the average drop is a sphere with a 0.25 inch diameter. A conservative number of 5 drops per minute is used based on the three interviews summarized in the table above. This yields $1.9 \mathrm{E}-4$ gallons/minute or 97.1 gallons/year.

Thus, based on SRS experience with several thousand Hanford connectors, the average failure rate is estimated to be $9.6 \mathrm{E}-3 / \mathrm{yr} /$ connector with a nominal leak rate of 97 gallons/yr (1.4 gallons/5 days) per connector.

Based on this information, a frequency of $3.9 \mathrm{E}-2 / \mathrm{yr}$ is calculated for four Hanford connectors plus 100 feet of transfer lines in the Filter Cell which are under pressure and contain tetraphenylborate solids:

$$
\begin{gathered}
4.0 \mathrm{E}-2=(4 \text { connectors })(9.6 \mathrm{E}-3 / \mathrm{yr} / \text { connector }) \\
+(100 \mathrm{ft} \text { single wall })(2.0 \mathrm{E}-5 / \mathrm{yr} / \mathrm{ft} \text { for all leak rates, } \\
\text { see Sec. } 6 \text { below })
\end{gathered}
$$

Expressed alternatively, there is a $95 \%$ chance that there will be no leaks within the first year of operation with the Filter Cell:

$$
\text { Probability (no leaks in } x \text { years, } x=1.3)=\exp \{(-4.0 \mathrm{E}-2)(1.3 \text { years })\}=0.95
$$

If a leak does occur, the average size leak will require more than a year to accumulate 100 gallons of slurry in the cell since the connectors dominate this frequency and have an average leak rate of 97 gallons/yr ( 1.4 gallons/5 days) per connector.

The frequency for large leaks $\geq 100$ gallons $/ 5$ days will be dominated by 100 feet of transfer lines in the Filter Cell which have a leak frequency of $1.2 \mathrm{E}-4 / \mathrm{yr}$ from 100 feet times $1.2 \mathrm{E}-6 / \mathrm{ft} / \mathrm{yr}$ for catastrophic leaks (see Sec. 6.0 below). Expressed alternatively, for large leaks $\geq 100$ gallons $/ 5$ days, there is a $95 \%$ chance that no leaks will occur within 427 years of operation with the Filter Cell.

Probability (no leaks in $x$ years, $x=427)=\exp \{(-1.2 E-4)(427$ years $)\}=0.95$ 


\subsection{FREOUENCY OF LEAKS IN DOUBLE-WALL TRANSFER LINES:}

The leak frequencies for the transfer lines are developed with the Thomas Model [18] which uses data from piping experience from all over the world. A frequency of $2.0 \mathrm{E}-6 / \mathrm{yr} / \mathrm{ft}$ is obtained for leaks of all sizes from transfer lines which are doublewall, i.e., have a cylindrical collection volume. This value is obtained from:

frequency for catastrophic, i.e. large, leaks of $1.2 \mathrm{E}-6 / \mathrm{yr} / \mathrm{ft}[18,19]$. A single value independent of pipe diameter, wall thickness and operating pressure is used since experience has shown [18] that designers adequately provide pipe specifications according to the application. This practice maintains a relatively constant ratio of strength versus application. The net result is that the frequency of observed leak rates depends primarily on pipe length.

divided by 0.06 to convert catastrophic (large) leak frequencies into the mean frequency for leaks inclusive of all leak rates for a given pipe.

multiply by the length of the transfer line/pipe in feet.

multiply by 0.1 to account for common causes and/or failure modes between the inner and outer pipes in a double-wall transfer line. Common cause failure rates have been generated over a wide range of component types [20]. Ref. 20 based on combinations of SRS and generic data showed that the single failure rate of a component can be multiplied by 0.1 to obtain a reasonable, and usually conservative, estimate of the common cause failure rate. Potential root causes for common cause failures in double-wall transfer lines are: stress corrosion cracking, fatigue, corrosive liquids, manufacturing defects, incorrect installation, residual stresses in the heat affect zone around welds, uneven loading during installation, operation or subsequent settling, water hammer, or any failure of the inner pipe which subsequently transmits the same cause to the outer pipe. Sampling of the annular volume between the double-wall pipe for the presence of slurry, solids or radioactivity can provide a warning for some but not all of these failure modes which are a mix of sudden versus gradual failures. However, the protection which is provided by sampling the annular volume between the pipe in the transfer line will create an additional, but undetermined, margin of conservatism in the above recommended value of $2.0 \mathrm{E}-5 / \mathrm{ft} / \mathrm{yr}$.

Finally, additional evidence supports the statement that the leak frequency of $2.0 \mathrm{E}-6 / \mathrm{ft} / \mathrm{yr}$ for double-wall transfer lines is conservative. Previously it was found while performing the Probabilistic Risk Assessment for K-Reactor at SRS [19] using the Thomas Model that in some applications the mean value for the failure of 
single wall, high quality, stainless steel piping used in the US reactor industry could be reduced especially when referenced to the failure rates recommended by Science Applications International, Corp. [21], WASH-1400 [22] and a recently documented SRS Generic Data Base Development [11]. Since it is not known what portion of this reduction applies in this case, no credit is taken at this time other than to note that the leak rate of $2.0 \mathrm{E}-6 / \mathrm{ft} / \mathrm{yr}$ for double-wall transfer lines as conservative.

Given a conservative frequency of $2 \mathrm{E}-6 / \mathrm{yr} / \mathrm{ft}$ for all leaks for the doubled-wall transfer lines and the following lengths, the leak frequencies are calculated to be:

less than $4 \mathrm{E}-4 / \mathrm{yr}$ for the transfer line from Tank 48 to the Filter Cell $(<200$ feet)

less than $8 \mathrm{E}-4 / \mathrm{yr}$ for the transfer line from Tank 48 to Tank 49 ( $<400$ feet)

less than $4 \mathrm{E}-3 / \mathrm{yr}$ for the transfer line from Tank 49 to "Late Wash" $(\sim 2,000$ feet). 
WSRC-RP-94-516, Rev. 0

\subsection{CONCLUSIONS}

1) A single value of $1.1 \mathrm{E}-3$ is estimated for the probability of an ignition source for tetraphenylborate solids present in either the Tank 48 or 49 annulus or in the Filter Cell of the ITP Facility.

2) This analysis parallels a similar analysis performed and reviewed recently for deflagration of gases/vapors inside Tanks 48 or 49 . The value of $1.1 \mathrm{E}-3$ is lower than that reported previously due to the reduced movement of solids towards the ignition source as compared to gas/vapor mixing and the reduced amount of electrical equipment. As before, a conservative margin is included here by doubling the intermediate result in order to bound the industrial observation that in as many as $50 \%$ of the cases of combustion, the source of ignition can not be determined.

3) This analysis indicates that the ranking of contributors to the probability of an ignition source is based on the possibility that equipment is damage from: (1) mishandling by personnel; (2) lightning; and (3) original installation and/or aging.

4) There is enough examples of lightning damage to safety equipment onand offsite to include this failure mode even for TPB solids. Considering studies with ignition of TPB with electrical sparks [2], it is assumed that one lightning strike to the facility, or close by, will not ignite the TPB inside the Tank 48 or 49 annulus or the ITP Filter Cell. By contrast, in an earlier analysis of deflagration of a gas/vapor inside Tank 48 or 49 [1], it was assumed that when a gas/vapor mixture was above the lower flammability limit, one strike would cause deflagration. Therefore, in the case of TPB solids for lightning to cause ignition, it must damage electrical equipment which in turn must provide a prolonged discharge of energy to cause combustion.

5) It is assumed that damage to electrical equipment will be discovered and repaired by at least the next cycle of calibration, tests or preventive maintenance. It is important that regular preventive maintenance and calibration of equipment be performed. For this analysis, it is assumed that this done quarterly.

6) Based on SRS experience with over 4,000 Hanford connectors in F- and HCanyons, the average failure rate as $1.1 \mathrm{E}-6 / \mathrm{hr} /$ connector, or $1.0 \mathrm{E}-2 / \mathrm{yr} /$ connector with a nominal leak rate of 100 gallons/yr.

7) Hydrostatic testing will be performed as described by cognizant engineers for configuration or filter changes in the Filter Cell. This testing should reduce the leak frequency used in this analysis since it was based on the performance of the Hanford connectors in F- and $\mathrm{H}$-Canyons where hydrostatic testing is not routine. 
8) In the Filter Cell, the frequency for a leak $\leq 100$ gallons in 5 days is $4 \mathrm{E}-2 / \mathrm{yr}$ for four Hanford connectors plus 100 feet of transfer lines which are under the highest pressure and contain the largest concentrations of tetraphenylborate solids. This implies that there is a $95 \%$ chance that there will be no leaks within the first year of operation with the Filter Cell. If a small leak occurs, the average size leak will require more than a year to accumulate 100 gallons of slurry in the cell.

9) In the Filter Cell, if a large leak ( $\geq 100$ gallons/5 days) occurs, it will be dominated by the 100 feet of single-wall transfer lines in the Filter Cell with a leak frequency of $1.2 \mathrm{E}-4 / \mathrm{yr}$. This implies that there is a $95 \%$ chance that no leaks will occur within 427 years of operation with the Filter Cell.

10) For small leaks, the slurry is assumed dry and can be ignited.

11) For large leaks, the slurry is assumed wet and can not be ignited. In the Tank 48 or 49 annulus, large leaks (approaching 50 gallons/day) will flow [24] to a sensor(s) and be detected before drying and becoming susceptible to ignition.

12) In the Tank 48 or 49 annulus, small leaks are of the greatest concern since the reduced flow rate delays detection and allows time for the slurry to accumulate and dry. A value of $2 \mathrm{E}-3 / \mathrm{yr}$ is estimated for the frequency of a small leak that can go undetected and deposit more than 900 gallons in the Tank 48 annulus. Given that there is a $2 \mathrm{E}-3$ probability that a small leak will occur in one year, there is a $95 \%$ chance that none of these leaks will occur in 25 years. Should a leak occur, the time it would take to accumulate 900 gallons would range from 18 days to 40 years where the longer times are most likely.

13) A value of $2.0 \mathrm{E}-6 / \mathrm{yr} / \mathrm{ft}$ is estimated as an upper bound for the frequency of all size leaks from doubled-wall transfer lines. Based on this value, leak frequencies are calculated to be less than $4 \mathrm{E}-4 / \mathrm{yr}$ for the transfer line from Tank 48 to the Filter Cell ( $<200$ feet); less than $8 \mathrm{E}-4 / \mathrm{yr}$ for the transfer line from Tank 48 to Tank 49 ( $<400$ feet); and less than $4 \mathrm{E}-3 / \mathrm{yr}$ for the transfer line from Tank 49 to "Late Wash" Tank $(\sim 2,000 \mathrm{feet})$. In a double-wall transfer line, it is not possible to detect the onset of all common cause failures. Therefore, it is anticipated that the remaining common cause failure modes which are more difficult to detect are the dominate contributors to the failure rate. 


\subsection{REFERENCES}

[1] D. S. Cramer and H. A. Ford, Probability of Ignition Sources in Waste Tanks 48 or $49(U)$, WSRC-RP-93-770, May 1993.

[2] J. E. Johnston, Environmental Testing - Explosive Hazards of Tetraphenyl Borate Flammability, Transmittal of results obtained by the du Pont Engineering Service Division at the Engineering Test Center to D. D. Walker, January 5, 1988. This report is Appendix B in Ref. 3.

[3] D. D. Walker, Combustibility of Tetraphenylborate Solids (U), WSRC-RP-89-261, May 3, 1989.

[4] G. D. Wyss, A. L. Camp, L. A. Miller, S. E. Dingman, D. M. Kunsman (SNL), G. T. Medford (SAIC), Accident Progression Event Tree Analysis for Postulated Severe Accidents at $N$ Reactor $(U)$, SANDIA89-2100, pp. C-24 through C-28, June 1990 . Work performed by Sandia for Westinghouse Hanford Company. This report also available under the Westinghouse document number WHC-MR-0045.

[5] R. E. Vail and B. C. Benhardt, SRS-Specific Data Compilation in Support of Human Error Data Base Development (U), WSRC-TR-94-0109, February 1994.

[6] J. E. Held, Human Reliability Analysis of DWPF Calibration Activities (U), SRTHFE-930011, May 1993.

[7] D. S. Cramer, Data Base Development and Equipment Reliability for Phase 1 of the Probabilistic Risk Analysis (U), DPST-87-642, October 8, 1987.

[8] NUREG/CR-4772, "Accident Sequence Evaluation Program Human Reliability Analysis Procedure," A. D. Swain III, February 1987. This method is known as ASEP.

[9] NUREG/CR-1278, "Handbook of Human Reliability Analysis With Emphasis on Nuclear Power Plant Applications," A. D. Swain and H. E. Guttman, August 1983.

[10] M. K. Gupta, T. E. Britt, B. J. Shapiro and A. Beyrer, Accident Analysis for In-Tank Precipitation Process Nitrogen Purge System (U), WSRC-TR-93-169/Rev. 2, January 1994.

[11] C. H. Blanton and S. A. Eide (LATA), Savannah River Site Generic Data Base Development $(U)$, WSRC-TR-93-262, June 30, 1993.

[12] G. R. Caskey, K. E. Kehr, M. H. Hilker, D. E. Rawl, and R. F. Mittelberg, Leak History: Reactor Primary Coolant Systems (U), WSRC-RP-89-126, April 21, 1990.

[13] T. C. Hsu, Type III Waste Tanks Failure Frequency (U), HLW-HLE-94-0522, March $14,1994$.

[14] S. V. Topp, Probabilities for Reactor Tank Cracks, SRL-PRA-91-0157, May 28, 1991.

[15] E. P. Shine, Estimating the Failure Rate When No Failures Have Occurred (U), SCS-ASG-92-077, October 9, 1992. 
[16] J. A. Smith, Private Communication, April 6, 1984.

[17] H.-O. Peitgen and P. H. Richter, The Beauty of Fractals, Springer-Verlag, Berlin Heidelberg, 1986.

[18] Thomas, H. M., Rolls-Royce and Associates, Ltd., Pipe and Vessel Failure Probability. Reliability Engineering 2, February 1981, pages 83-124.

[19] M. D. Brandyberry, D. S. Cramer, W. H. Horton, K. D. Kirby (SAIC), V. E. Logan, B. J. Shapiro (SAIC), D. A. Sharp, B. S. Singer (SAIC), J. A. Smith, S. P. Tinnes, S. V. Topp, J. E. West (SAIC), and H. E. Wingo, SRS PRA of Reactor Operation - Level I Internal Events $(U)$, WSRC-RP-89-570, June, 1990.

[20] H. A. Ford, Common Cause Failure Rates for Select Components in the Rev. 1 Level 1 PRA Derived with MGL Methodology (U), WSRC-RP-92-1193, October 1992. Based on work performed by Los Alamos National Laboratory as CALC-NOTE N-6-92-R184 Rev. 0, August 1992.

[21] D. S. Cramer, SRP Generic Database (SAIC/NY 85-8-14). Internal Report DPST-86401, April 17, 1986, prepared by J. Fragola and E. P. Collins, Science Applications International Corp., New York, NY.

[22] Reactor Safety Study, An Assessment of Accident Risks in U. S. Commercial Nuclear Power Plants. Table III 6-10 entitled "Reported Pipe Failure Rates." WASH1400 (NUREG 75/014), October 1975.

[23] B. M. Hanlon, Tank Farm Surveillance and Waste Status Summary Report for January 1994, WHC-EP-0182-UC-721, May 1994.

[24] D. D. Walker, Private Communication, June 1994. Engineering judgment developed from experiments conducted with solutions of tetraphenylborate (TPB) of varying wt.\% water and solids.

[25] T. B. Powers and S. D. Morales, SY Tank Farm Ventilation, Isolation Option, Risk Assessment Report (U) , WHC-EP-0579, July 1992. Also T. B. Powers, Private Communication with D. S. Cramer, May 10-14, 1993. 


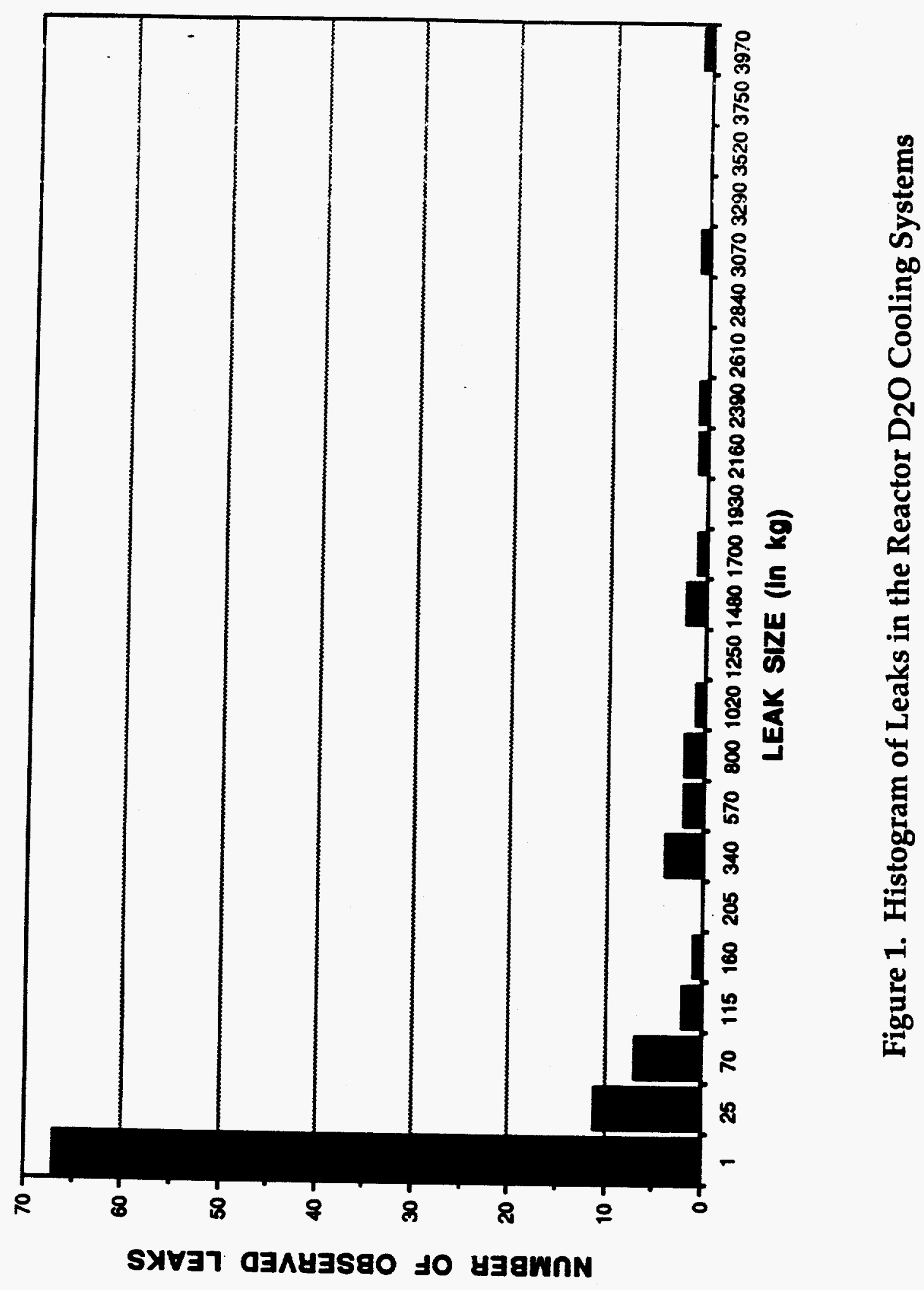

$\stackrel{\infty}{N}$ 